\title{
A Study on Factors affecting Productivity of Outpatient Pharmacy of a Corporate Hospital
}

\author{
Dr M V Rao ${ }^{1}$, Dr P Srinivas ${ }^{2}$, Dr C D Jaya Kumar ${ }^{2}$, Dr J Prerana ${ }^{2}$ \\ ${ }^{1}$ Associate Professor ${ }^{2}$ Resident(Kamineni Institute of Medical Sciences, Narketpally (TS), India)
}

\begin{abstract}
A brief study was carried out in outpatient pharmacy of a tertiary care corporate hospital, to evaluate its productivity, especially in relation to prescriptions being dispensed and its impact on revenue Relevant data has been collected from the outpatient departments, pharmacy records and personal interviews with concerned staff and from patient feedback. Number of prescriptions generated vis-à-vis number of daily outpatient visits, those reaching the pharmacy and out of which the number which could be dispensed and the reasons for bouncing of the prescriptions was analyzed.Patient feedback was also obtained through a limited survey on reasons for their not collecting prescribed medicines from the hospital's outpatient pharmacy. Based on the study findings, certain recommendations have been made, for enhancing the productivity of the pharmacy.
\end{abstract}

Keywords: Outpatient pharmacy, Revenue, Prescriptions, Dispensing, Patient feedback

\section{Introduction}

Outpatient retail pharmacy is a very significant contributor to the overall financial success of the hospital. Lack of retail expertise is a common problem in health-system pharmacy operations. There are opportunities to drive new revenues through better inventory management, improving the outpatient pharmacy management, prescribing \& dispensing of medicines, managing the discharge prescriptions and emergency department fills. In addition all these increase in patient satisfaction, and decrease readmissions with better drug compliance following discharge. ${ }^{1}$

\section{Methods}

Study in brief, the factors affecting the productivity of outpatient pharmacy of a corporate hospital, with special emphasis on prescription generation, dispensing and patient feedback.

3.1 One month data on daily number of prescriptions reaching the pharmacy, number of prescriptions bouncing, the reasons for non-availability of medicines was collected from the pharmacy records, MIS and interviews with pharmacy and administrative staff

3.2 Reasons for bouncing of prescriptions were categorized as following.

a) Prescribed Brand of the drug not available in the pharmacy

b) Prescribed drug not available in the hospital formulary (New drug)

c) Prescribed drug not in stock in the pharmacy though listed in the hospital formulary.

3.3. A survey was carried out to obtain patient feedback, through a questionnaire, on their experience on the issue, with the pharmacy.

3.4. One week data on number of patients visiting outpatient departments, number of prescriptions generated containing medications was obtained from outpatient secretaries.

3.5. Compilation and analysis of data was carried out using MS Excel.

\section{Results}

4.1. On an average, outpatient visits per day were 135 , out of which, $76 \%$ (102cases) were prescribed with medicines. $71(69.6 \%)$ of those prescriptions were reaching the OP pharmacy and $31(30.4 \%)$ were not reaching the pharmacy.

4.2. Out of 71 prescriptions reaching the pharmacy, $12(16.90 \%)$ were bouncing due to the following reasons

i. $\quad$ Prescribed Brand of the drug not available in the pharmacy ( 3 occasions)

ii. $\quad$ Prescribed drug not available in the hospital formulary (New drug to formulary) (5 occasions)

iii. Prescribed drug not in stock in the pharmacy though listed in the hospital formulary (4 occasions).

Overall, $42 \%$ of prescriptions are either not reaching the pharmacy or bouncing. 


\section{Figures and Tables}

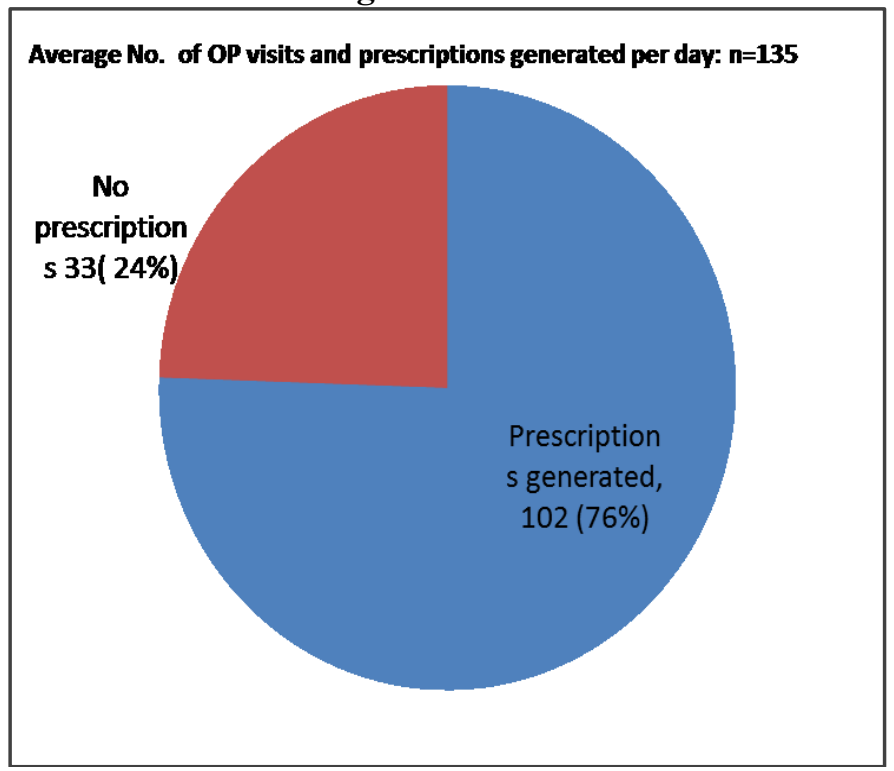

Fig 1 -Number of Patient visits to the Out Patient Department and prescriptions generated

\section{Outcomes of generated prescriptions: $n=102$}

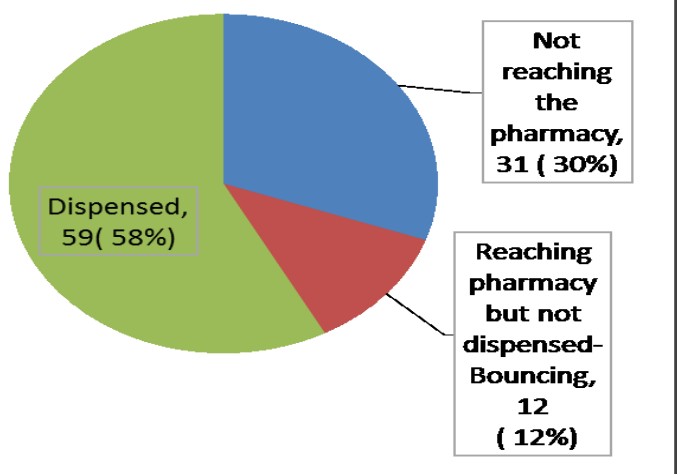

Fig-2- Outcome of Prescriptions generated from OP

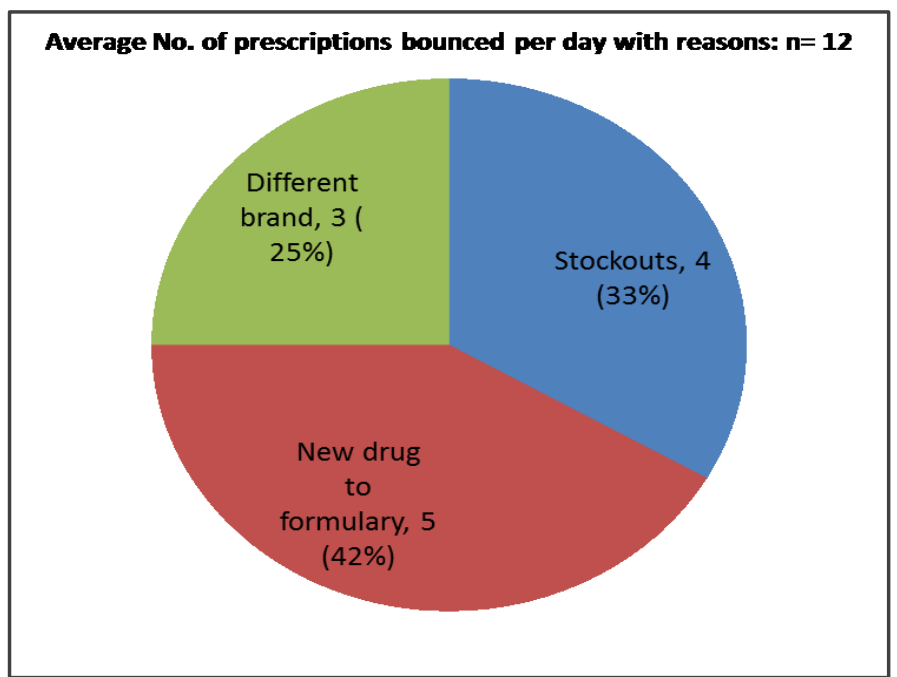

Fig 3: Reasons for bouncing of prescriptions 


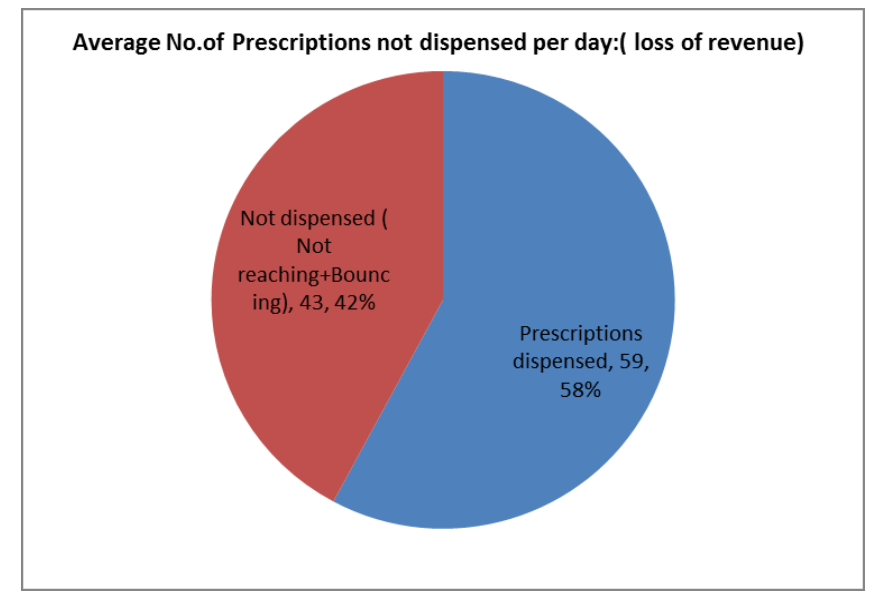

Fig 4: Prescriptions causing loss of revenue

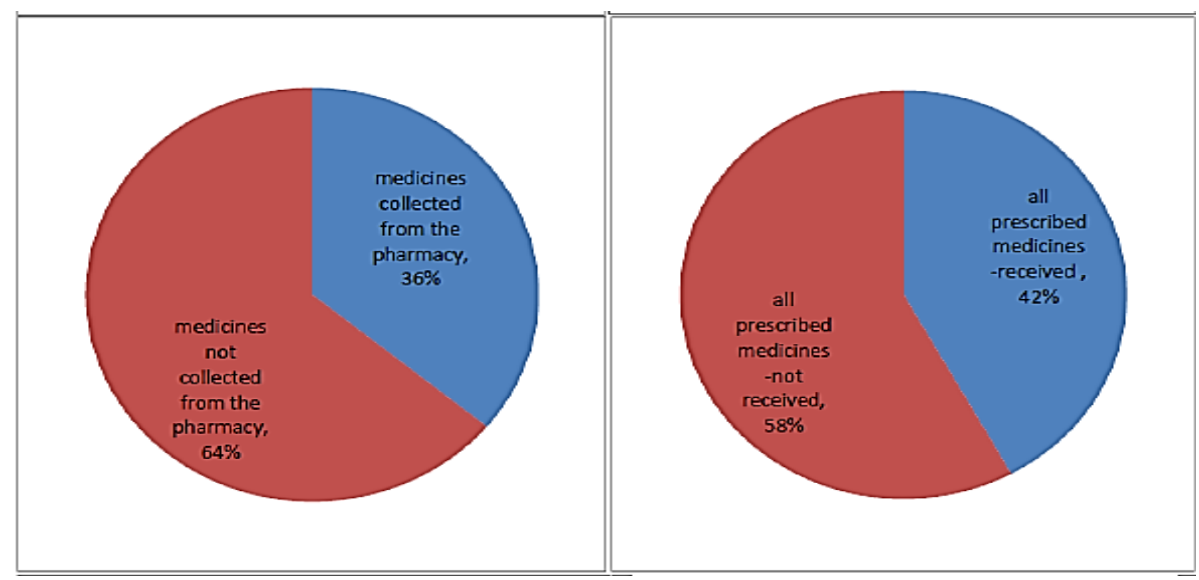

Fig-5: Responses from the patients to the questionnaire

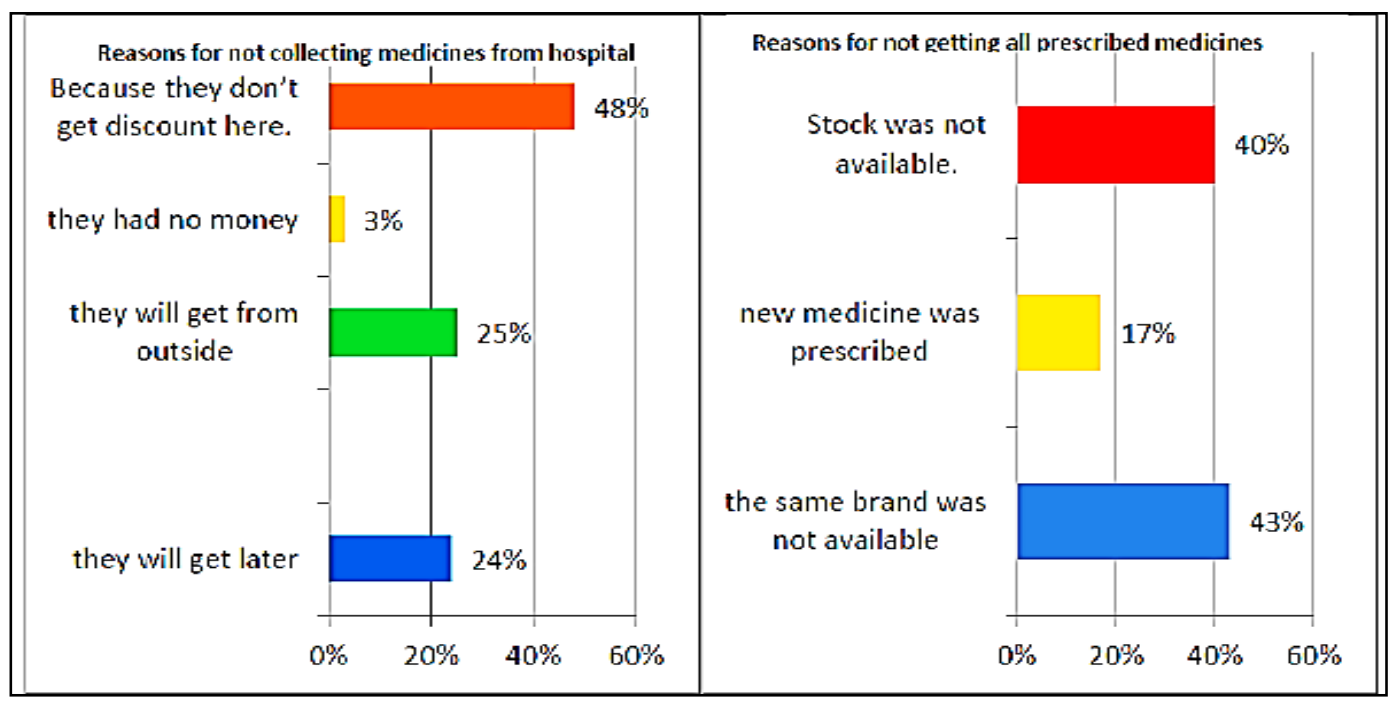

Fig-6: Responses from the patients to the questionnaire

\section{Discussion and Recommendations}

The results showed that $42 \%$ of the revenue was being lost either due to patients not reaching the pharmacy for purchase or prescriptions not been dispensed due to non-availability of drugs prescribed. To address this issue of improving the productivity of the pharmacy, the possible solutions that could be adapted in pharmacy management were identified as mentioned below-. 


\begin{tabular}{|c|c|c|}
\hline Issue & Strategy & Benefit/Outcome \\
\hline \multirow[t]{5}{*}{ Medication costs } & $\begin{array}{l}\text { Efficient purchasing and contracting of } \\
\text { drugs }\end{array}$ & Reduction in overall drug expenditure \\
\hline & Inventory management & \\
\hline & $\begin{array}{l}\text { Reducing waste and repackaging where } \\
\text { appropriate }\end{array}$ & \\
\hline & Medication use evaluation criteria & \\
\hline & P\&T committee formulary management & \\
\hline \multirow[t]{2}{*}{ Revenue generation } & Telepharmacy & $\begin{array}{l}\text { Improved order processing speed, expanded } \\
\text { clinical pharmacy services, avoidance of } \\
\text { medication cost }\end{array}$ \\
\hline & Specialty pharmacy & $\begin{array}{l}\text { Revenue capture, reduced medication costs, } \\
\text { improved patient compliance }\end{array}$ \\
\hline \multirow[t]{4}{*}{$\begin{array}{l}\text { Reducing harmful medication } \\
\text { errors }\end{array}$} & $\begin{array}{l}\text { Technology: integrated EMR, BCMA, smart } \\
\text { pumps }\end{array}$ & Reduced medication administration errors \\
\hline & Department dashboard & Staff awareness of safety measures over time \\
\hline & Medication error review process & $\begin{array}{l}\text { Staff awareness of medication errors and } \\
\text { ways to prevent errors at point of care }\end{array}$ \\
\hline & $\begin{array}{l}\text { Exposure to national programs established } \\
\text { by ASHP, ISMP, FDA }\end{array}$ & $\begin{array}{l}\text { Knowledge about medication safety from a } \\
\text { broad network }\end{array}$ \\
\hline \multirow[t]{3}{*}{$\begin{array}{l}\text { Pharmacy practice model } \\
\text { advancement }\end{array}$} & $\begin{array}{l}\text { Clinical privileging and credentialing of } \\
\text { acute and ambulatory care pharmacists }\end{array}$ & Expanded pharmacist clinical responsibilities \\
\hline & $\begin{array}{l}\text { Advocacy efforts on local, state, and } \\
\text { national level }\end{array}$ & $\begin{array}{l}\text { Pharmacist provider status, billing for } \\
\text { services }\end{array}$ \\
\hline & Recruit qualified pharmacists & Expanded pharmacist clinical responsibilities \\
\hline \multirow[t]{2}{*}{ Student experiential education } & $\begin{array}{l}\text { Involve pharmacy residents in precepting } \\
\text { student rotations }\end{array}$ & $\begin{array}{l}\text { Mentorship for students, precepting } \\
\text { experience for residents }\end{array}$ \\
\hline & $\begin{array}{l}\text { Involve students in medication history and } \\
\text { reconciliation }\end{array}$ & $\begin{array}{l}\text { Improve transitions of care, provide } \\
\text { additional learning opportunities for } \\
\text { students }\end{array}$ \\
\hline
\end{tabular}

Table 1: Possible strategies for improving pharmacy management ${ }^{2}$

Further, the factors which encourage patients to purchase their prescriptions from a hospital Outpatient pharmacy are- ${ }^{3}$

1. Attitude of pharmacy personnel

2. Accessibility and convenience of pharmacy location

3. Quality and cost of drugs

4. Conducive physical environment

5. Availability of prescribed drugs

6. Timeliness of service delivery

Stock outs in pharmacy can be avoided by proper inventory management for which the hospital administration can use achecklist. ${ }^{4}$ In addition, sample of records should be reviewed and informal interviews and observations shall be carried out to answer the following questions.

\begin{tabular}{|c|c|c|}
\hline \multicolumn{2}{|c|}{ Table-2 : Checklist for proper inventory management } & \\
\hline \multicolumn{2}{|r|}{ 1. Record-keeping } & $\mathrm{Y} / \mathrm{N}$ \\
\hline$\bullet$ & $\begin{array}{l}\text { Are the inventory records up-to-date? Check the stock cards/ details in information system to see how recently they } \\
\text { have been used. }\end{array}$ & \\
\hline$\bullet$ & Are the inventory records accurate? Do they agree with what is on the shelves? & \\
\hline$\cdot$ & Is the arithmetic correct? & \\
\hline • & Are complete records kept of the quantities of medicines and supplies dispensed to patients? & \\
\hline$\bullet$ & Do the calculated quantities on the stock cards generally agree with the physical inventory quantities? & \\
\hline \multicolumn{2}{|r|}{ 2. Stock levels } & \\
\hline$\bullet$ & Are minimum and/or maximum stock levels calculated for each item? & \\
\hline • & Has the average monthly consumption been calculated recently and accurately? & \\
\hline$\bullet$ & Has the store successfully avoided stock-outs? & \\
\hline \multicolumn{2}{|r|}{ 3. Quality assurance } & \\
\hline & $\begin{array}{l}\text { Is there a system for performing quality checks to make certain that all medicines are usable by patients (that is, not } \\
\text { expired or damaged)? }\end{array}$ & \\
\hline
\end{tabular}




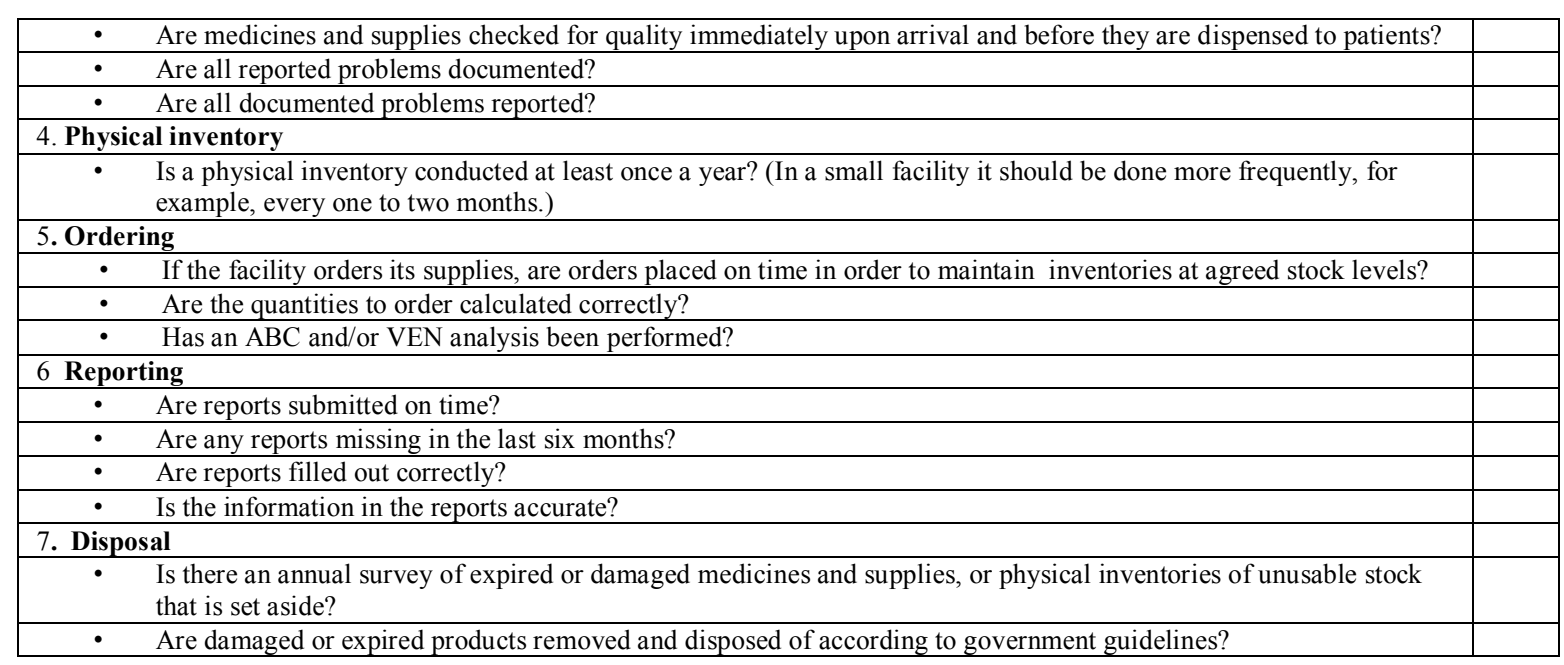

Based on the outcome of study and review of literature the following recommendations have been suggested for improvement in the pharmacy productivity:

5.1. Signage to be positioned in the reception and outpatient areas, to show the location and directions to the pharmacy.

5.2. Any incentives/ discounts on purchases to be prominently displayed and communicated to patients to encourage purchases from the outpatient pharmacy.

5.3. Use of Generic Names of drugs: Consultants should be encouraged to write the generic names of drugs in the prescriptions. Number of medicines with the same ingredients with different brand names bounce sharply, evokes competition in Pharmaceutical Industry to influence physicians to prescribe their product. In prescribing, physician ought to adapt Formulary ${ }^{5}$. Medical Council of India, with the approval of the Central Government, who makes the regulations relating to the Professional Conduct, Etiquette and Ethics for registered medical practitioners, insists in chapter 1.5, use of Generic names of drugs: Every physician should, as far as possible, prescribe drugs with generic names and he / she shall ensure that there is a rational prescription and use of drugs. ${ }^{6}$

5.4. Pharmacy technicians conduct daily rounds with discharge planners to identify patients ready for discharge, and then offer to fill discharge scripts before the patient leaves. In this way patients get their medicines, as well as intensive one-on-one counseling. This procedure generates a valuable revenue stream, has great value in improving patient satisfaction scores and in reducing readmissions ${ }^{1}$

5.5. Procurement is to be stream lined by effective consultations with the clinicians to include commonly prescribed medicines in the formulary. Accordingly the formulary needs to be regularly updated. Up to date information shall be circulated to all clinicians about the drugs position in the pharmacy. Stock out list also shall be circulated.

5.6.Drug and Therapeutics Committee should involve with drug selection, use of antibiotics, hospital infections in order to influence the preparation and composition of an essential-drug list or formulary and effectively control supply of high-quality products. ${ }^{7}$

5.7.Effective inventory control mechanism, including training pharmacists in inventory control should be instituted in the pharmacy, to ensure adequate stock, and prevent stock outs. Hospital administrators to have checks on the pharmacy operations, through checklists as stated below:-

5.8 Pharmacy Inventory Management: Checklist for Hospital Administrator ${ }^{4}$ as described in table-2

\section{Conclusion}

Outpatient pharmacy, in a corporate hospital plays an important role in patient care in that it makes available the prescribed medicines at ease of comfort for the patients and without financial burden, thus facilitating effective patient outcomes as well as meeting their satisfaction. The department demands effective inventory control and quality management to boost the hospital revenues. As such, review studies of functioning of hospital pharmacy would immensely contribute to enhancement of its quality and productivity.

\section{Acknowledgements}

The authors sincerely acknowledge the support and cooperation of all concerned staff of the hospital for sparing their valuable time and supplied all necessary information for the study and special acknowledgments to the patients who gave the valuable feedback. 


\section{References}

[1] Fred Gebhart, Outpatient pharmacy can boost hospital revenues, patient outcomes - INTERNET: Date of publication-2012,OCT15[ cited-2014].Available from: http://drugtopics.modern medicine.com/drug-topics/news/modernmedicine/modern-medicine-featurearticles/outpatient-pharmacy-can-boost-hospi?page=full\#sthash.9IZNInLR.dpuf

[2] Khandoobhai,Anand, and Robert J. Weber. "Issues Facing Pharmacy Leaders in 2014: Suggestions for Pharmacy StrategicPlanning." Hospital pharmacy 49.3 (2014): 295-302.

[3] Afolabi, M. O., E. R. I. Afolabi, and B. A. Faleye. "Construct validation of an instrument to measure patient satisfaction with pharmacy services in Nigerian hospitals." African health sciences 12.4 (2013): 538-544

[4] Sylvia Vriesendorp, et,al .Management Sciences for Health. Health Systems in Action: An e Handbook for Leaders and Managers. Cambridge, MA: Management Sciences for Health, 2010. Available online at http://www.msh.org/sites/msh.org/files/msh_ehandbook_complete.pdf; 7.52

[5] Setiawan, Monica Widyawati."Behavior Changes by Interactional Model of Communication on Physician Prescription." Health Care 52 (2014):54.

[6] MCI India, Code Ethics Regulations, 2002 http: //www.mciindia.org/RulesandRegulations/CodeofMedicalEthicsRegulations2002.aspx

[7] Hepler, Charles D., and Linda M. Strand. "Opportunities and responsibilities in pharmaceutical care." Am J Hosp Pharm 47.3 (1990): 533- 543 . 